\title{
Measuring the Performance of Hospitals in Lebanese qadas Using PCA- DEA Model
}

\author{
Alissar Nasser $^{1}$ \\ ${ }^{1}$ Faculty of Economic Sciences and Business Administration, Lebanese university, Hadath, Lebanon \\ Correspondence: Alissar Nasser, Faculty of Economic Sciences and Business Administration, Lebanese university, \\ Hadath, Lebanon. Tel: 961-5-463-621. E-mail: Alissar.nasser@gmail.com, alissar.nasser.1@ul.gov.lb
}

Received: October 16, 2018

Accepted: November 1, 2018

Online Published: January 18, 2019

doi:10.5539/cis. v12n1p23

URL: https://doi.org/10.5539/cis.v12n1p23

The research is financed by the Lebanese University.

\begin{abstract}
We study in this paper the performance of Hospitals in Lebanon. Using the nonparametric method Data Envelopment Analysis (DEA), we are able to measures relative efficiency of Hospitals in Lebanon. DEA is a technique that uses linear programming and it measures the relative efficiency of similar type of organizations termed as Decision Making Units (DMUs). In this study, due to the lack of individual data on hospital level, each DMU refers to a qada in Lebanon where the used data represent the aggregation of input and outputs of different hospitals within the qada. In DEA, the inclusion of more number of inputs and /or outputs results in getting a more number of efficient units. Therefore, selecting the appropriate inputs and outputs is a major factor of DEA results. Therefore, we use here the Principal Component Analysis (PCA) in order to reduce the data structure into certain principal components which are essential for identifying efficient DMUs. It is important to note that we have used the basic BCC-input model for the entire analysis. We considered 24 DMUs for the study, using DEA on original data; we got 17 DMUs out of 24 DMUs as efficient. Then we considered 1 PC for inputs and 1 PC for output with almost 80 percent variances, resulting in 3 DMUs as efficient and 21 as inefficient. Using 1 PC for input and 2 PCs for output with 90 percent variance for both input and output, we got 9 DMUs as efficient and 15 DMUs as inefficient. Finally, we have attempted to identify the efficient units with 2 PCs and for 2 PCs for input and outputs with variance more than 95 percent, resulting in 10 efficient DMUs and 14 inefficient DMUs. In Principal Component analysis, if the variance lies between 80 percent to- 90 percent it is judged as a meaningful one. It is concluded that Principal Component Analysis plays an important role in the reduction of input output variables and helps in identifying the efficient DMUs and improves the discriminating power of DEA.
\end{abstract}

Keywords: data envelopment analysis, principal component analysis, input, output, data reduction, efficiency

\section{Introduction}

According to the United Nations High Commissioner for Refugees (UNHCR), Lebanon hosts more than one million refugees from Syria, 80.9\% of which are women and children as of December 2017 (UNHCR, 2017). Therefore, studying the Lebanese healthcare system becomes essential for the government and for the decision makers. The available resources to satisfy the primary healthcare need of people are limited. According to (Antonios and Mikhael, 2018) healthcare expenditure rose at a compounded annual growth rate of $4.1 \%$ during 2011-2016, to reach almost \$3.5B. Therefore it is important to maintain an efficient healthcare system to handle the increasing demand in the healthcare. Efficiency improvement, cost reduction, and introduction of new technology will contribute to the existence of an efficient healthcare system (Morrisette and al., 2015).

Asandului and al. proved that the improvement of a population's health is dependent on an equitable and efficient healthcare system (Asandului and al. 2014). But the improvement in the healthcare system necessitate identification of areas of improvement which is not an easy process due to the unavailability of data in Lebanon related to private and/or public healthcare providers.

The healthcare system in Lebanon is divided into public and private health providers with several financing bodies and various laws and regulations (Reindel and Zucco, 2010). The health insurances bodies are the National Social Security Fund (NSSF) established in 1963 to provide employees and their dependents with national insurance 
coverage, army and Cooperative of Government Employees provide civil servants the insurance coverage. Union or body like union of engineers covers engineers and their dependants through private insurance. The Ministry of public Health $(\mathrm{MOPH})$ insures the remaining uninsured people; the beneficiaries are majority of the population, about 53.3\% according to surveys conducted by the central Administration of statistics in 2009 (cas, 2009).

Lebanon was always known for its healthcare services and medical institutions. The 1975 war and recently the influx of Syrian refugees have weakened the healthcare system. Despite his excellence in health services, Lebanon has one of the most expensive healthcare systems in the world (Sen and Mehio-Sibai, 2007). Lebanon has a high out of pocket health expenditure which leads to exposure of households to financial risk as a result of ill health (Salti and al. 2010). Ammar, the general director of the Ministry of public health in Lebanon presented in his report entitled the health reform in Lebanon, listed 12 key achievements of the ministry of public health over a 10 -year period. The document points out an increase in performance of the healthcare system, with improvement in supply of human resources, strength of the primary healthcare system, quality and accreditation improvement, and autonomy of public hospitals among others (Ammar, 2009).

The aim of this study is to create some idea as to the present state of the healthcare system in the country in the context of the available selected variables. Most of the studies that are reviewed used life expectancy at birth as output and health expenditure as inputs (Pourreza and al., 2017). Other studies such as Alfonso and St. Aubyn (Afonso and Aubyn, 2005) used number of beds and health employment as inputs. In a more recent study, Ibrahim and Daneshvar (Ibrahim and Daneshvar, 2018) the list of variables used were the number of hospital beds per 1000, number of physicians per 1000, health expenditure \% of GDP, life expectancy, adjusted life expectancy, infant mortality, and health expenditure per capita.

The objective of this paper is to evaluate efficiency and ranking efficient district hospitals DMUs by using Data Envelopment Analysis (DEA). Data used here consist of 24 Hospitals' qada in Lebanon with 5 inputs and 4 outputs representing. Results of this method is compared with the resulted obtained from using Principal Component Analysis PCA for variables reduction and then using DEA on the principal Components (PCs). The multivariate statistical method principal component analysis (PCA) is a data reduction technique, used to identify a small set of variables that account for a large portion of the total variance in the original variables. The idea of combining two methods (PCA \& DEA) was proposed by Hoshini and Udea in 1997 and developed by Zhu in 1998 (Zhu, 1998). He combined this statistical method with based models of DEA and proposed some new models for evaluating the efficiency of DMUs. Another paper studied the performance Efficiency of Hospitals in India (Annapoorni and Prakash, 2016).

This paper is organized as follows: In Section 2, DEA method is presented, in section 3 PCA method is presented. Section 4 presents results from different PCA-DEA models for evaluating and ranking DMUs with projected data set. Section 5, the conclusion is drawn.

\section{DEA Method}

Data Envelopment Analysis (DEA) is a method used to measure the relative efficiency of decision making units (DMUs). Farrell considers efficient DMUs those who have high single output to single input ratio, which mean so maximizing the production process to get higher output-to-ratio. However, when there are multiple inputs and outputs, finding the relative efficiency become complicated. Charnes, Cooper and Rhodes extended Farrell's idea to multiple output/input ratio and they proposed the CCR model in 1978 (Charnes and al. 1978). CCR model is constant returns to scale which mean that an increase in inputs results in an increase in outputs which is not hold in practice due to many factors. So Banker, Charnes and Cooper proposed another model, named BCC in 1984 (Banker and al., 1984). The BCC model is a variable return to scale which identifies whether a DMU is operating in increasing, decreasing or constant returns to scale.

DEA can be input-oriented or output-oriented models both seek to maximize efficiency of DMUs. Input-oriented model minimizes the inputs to reach a desired level of output, and output-oriented model maximize the outputs while input are at constant level. In general, input oriented model closely focuses on operational and managerial issues whereas output oriented model is more associated with planning and strategy. In this paper we are using the BCC-input oriented model to measure efficiency of qada's hospitals.

DEA has gained too much attention by researchers because of its successful applications and case studies. Assessment of bank branch performance (Yang, 2009), examining bank efficiency (Kordrostami and al, 2011), measuring the efficiency of higher education institutions (Johnes, 2006) Measuring the Performance Efficiency of Hospitals (Annapoorni and Prakash, 2016) are examples of using DEA in various areas.

\subsection{Mathematical Formulation}


DEA is commonly used to evaluate the relative efficiency of a number of DMUs. The basic DEA model in Charnes et al. (Charnes, 1978), called the CCR model, has lead to several extensions, most notably the BCC model of Banker et al. (Banker and al., 1984). Assume that there are $n$ DMUs, (DMUj: $j=1,2, \ldots, n$ ) which consume $\mathrm{m}$ inputs (xi: $\mathrm{i}=1,2, \ldots, \mathrm{m})$ to produce $\mathrm{s}$ outputs $(\mathrm{yr}: \mathrm{r}=1,2, \ldots, \mathrm{s})$. The $\mathrm{BCC}$ input oriented (BCC-I) model evaluates the efficiency of DMUo, DMU under consideration, by solving the following linear program:

$$
\begin{aligned}
& \quad \max \sum_{r=1}^{s} u_{r} y_{r j} \\
& \text { Subject to } \\
& \quad \sum_{i=1}^{m} w_{i} x_{i 0}=1 \\
& \quad \sum_{r=1}^{s} u_{r} y_{r j}-\sum_{i=1}^{m} w_{i} x_{i j} \leq 0, j=1,2, \ldots, n \\
& w_{i} \geq \varepsilon, i=1,2, \ldots, m \\
& u_{r} \geq \varepsilon, r=1,2, \ldots, s
\end{aligned}
$$

Where $x_{i j}$ and $y_{r j}$ (all nonnegative) are the inputs and outputs of the jth DMU, $w_{i}$ and $u_{i}$ are the input and output weights (multipliers) $\mathrm{x}_{\mathrm{i} 0}$ and $\mathrm{y}_{\mathrm{r} 0}$ are the inputs and outputs of DMUo. Also, $\varepsilon$ is non-Archimedean infinitesimal value for forestalling weights to be equal to zero. On account of the fact that basic DEA models identify more than one DMU as efficient units, finding the most efficient DMU is an issue.

The model gives efficiency scores, weights of inputs and outputs. In general, a DMU is considered to be efficient if it obtains a score of 1 and a score of less than 1 implies that it is inefficient.

The Method section describes in detail how the study was conducted, including conceptual and operational definitions of the variables used in the study, Different types of studies will rely on different methodologies; however, a complete description of the methods used enables the reader to evaluate the appropriateness of your methods and the reliability and the validity of your results, It also permits experienced investigators to replicate the study, If your manuscript is an update of an ongoing or earlier study and the method has been published in detail elsewhere, you may refer the reader to that source and simply give a brief synopsis of the method in this section.

\section{Principal Component Analysis}

Principal components Analysis (PCA) is a dimensionality reduction technique used to explain the variance structure of a set of variables through a few linear combinations of these variables (Jolliffe, 1986). The first few principal components generally describe up to $90 \%$ of the variance in the data. Thus the first few uncorrelated components can replace the original variables with minimum loss of information.

The main idea behind using PCA as a preprocessing step to DEA comes from the fact that more inputs/or outputs used in DEA model results in large number of efficient DMUs. Therefore the need to reduce the number of Inputs/or outputs with minimum loss of information is required.

Principal components are the uncorrelated linear combinations ranked by their variances or eigenvalues in descending order. Given a data set of inputs/or outputs variables $\mathrm{X}_{1}$ through to $\mathrm{X}_{\mathrm{n}}$, performing principal component analysis consists on creating linear combinations with maximum variance each of the $\mathrm{n}$ variables in the matrix $\mathrm{x}$, on the form:

$$
\begin{gathered}
\text { PC1 }=a_{11} X_{1}+a_{12} X_{2}+\cdots a_{1 n} X_{n} \\
\vdots \\
P C m=a_{m 1} X_{1}+a_{m 2} X_{2}+\cdots a_{m n} X_{n}
\end{gathered}
$$

Where $a_{m n}$ represents the coefficient for the mth principal component of the nth variable. The weights for each principal component are given by the eigenvectors of the correlation matrix or, if the original data were standardized, by the covariance matrix. The variance $(\lambda)$ for each principal component is given by the eigenvalue of the corresponding eigenvector. The components are ordered so that the first component (PC1) explains the largest possible amount of variation in the original data, subject to the constraint that the sum of the squared weights is equal to one (i.e. $a_{11}^{2}+a_{12}^{2}+\cdots+a_{1 n}^{2}=1$ ). The second component PC2 accounts for the maximum variance that is not accounted for by previous components and is uncorrelated with the first component. Then Subsequent components are identified that are uncorrelated with previous components; therefore, each component captures an additional dimension in the data, while explaining smaller and smaller proportions of the variation of the original variables until the number of principal components obtained is the same as the number of variables in the data set. The number of principal components extracted can also be defined by the user, and a common method 
used is to select components where the associated eigen value is greater than one.

Generally, inputs and outputs used in DEA analysis are positive, whereas the result of the principal components can be negative. Many studies showed that DEA model can be used without a change in the definition of efficient DMUs when using negative values or when using some transformation techniques to make PCA values positives (Annapoorni and Prakash 2016, Ali and Seiford 1990, Adler and Golany 2002).

\section{Data and Results}

\subsection{Data}

The data consists of 24 qada of Lebanon obtained from the ministry of public health MOPH-yearly bulletin for the year 2016. Some data were aggregated on Muhafaza level, and then we disaggregate the data using the distribution of hospitals within each muhafaza. The availability of health data is limited in Lebanon and most of the indicators at the national or muhafaza level. Analyzed here is obtained from the Directorate

The 24 qada are numbered from 1 to 24 are considered as DMU's. For each DMU four inputs are considered, they are,

1. IP1: Number of Hospitals: data available at the qada level.

2. IP2: Number of Beds available: data available at the muhafaza level

3. IP3: Number of Staff Nurses: data available at muhafaza level.

4. IP4: The population: data available at qada level.

For each DMU the following five outputs are considered, all available at qada level, they are:

1. OP1: Number of MOPH subsidized admissions

2. OP2:Number of MOPH subsidized in-patients

3. OP3:Total Caesarian Sections conducted

4. OP4: Number of MOPH subsidized hospitalized for cardiovascular cases.

5. OP5: Total cases benefiting from the Drug Dispensing Center.

\subsection{Results}

\subsubsection{Descriptive Statistics}

Descriptive statistics for input and outputs variables are presented in Table 1. It indicates that in 2016 the hospitals, on average, inpatients treated on MOPH was 6944, ranging from 387 thousand to 22696 with the standard deviation of 5451. The average number of caesarian, cardiovascular case and people benefiting from DDC were 2001, 1838 and 929 respectively with their standard deviations 2018,1517 and 831 .

Table 1. Descriptive Statistics

\begin{tabular}{lrrrrr}
\hline $\begin{array}{c}\text { Input } \\
\text { variable }\end{array}$ & N & Minimum & Maximum & \multicolumn{1}{l}{ Mean } & Std. Deviation \\
\hline IP1 & 24 & 1.0 & 19.0 & 5.92 & 4.89 \\
IP2 & 24 & 83.0 & 2314.0 & 485.83 & 509.40 \\
IP3 & 24 & 38.0 & 2732.0 & 424.00 & 568.28 \\
IP4 & 24 & 25370 & 488417 & 168294.42 & 142546.07 \\
OP1 & 24 & 1997.0 & 23963.0 & 9298.46 & 6412.32 \\
OP2 & 24 & 387.0 & 22696.0 & 6944.13 & 5451.56 \\
OP3 & 24 & 1 & 7152 & 2001.67 & 2018.94 \\
OP4 & 24 & 306.0 & 5783.0 & 1838.92 & 1517.42 \\
OP5 & 24 & 137.0 & 3960.0 & 929.71 & 831.90 \\
\hline
\end{tabular}

Source: Prepared by Author 


\subsubsection{Results for PCA-DEA}

Table $2(a, b)$ shows the percentage of variance of the principal components for input and output variables. For input dataset the first component accounts for approximately $90 \%$ of the variance whereas in output dataset the first component accounts for approximately $80 \%$ of the variance. Therefore, scores of first PC on input and first $\mathrm{PC}$ on output is used to estimate relative efficiency of hospitals.

Table 2. PCA coefficients for inputs and outputs

\begin{tabular}{|c|c|c|c|c|c|}
\hline \multicolumn{6}{|c|}{ Input (a) } \\
\hline Input variable & $\mathrm{C1}$ & PC2 & PC3 & \multicolumn{2}{|l|}{ PC4 } \\
\hline No of hospitals & -0.519 & 0.084 & -0.573 & \multicolumn{2}{|c|}{-0.629} \\
\hline no of Beds & -0.514 & -0.308 & -0.362 & \multicolumn{2}{|c|}{0.714} \\
\hline no of nurses & -0.496 & -0.518 & 0.649 & \multicolumn{2}{|c|}{-0.251} \\
\hline Population & -0.469 & 0.793 & 0.344 & \multicolumn{2}{|c|}{0.179} \\
\hline $\begin{array}{l}\text { Proportion } \\
\text { variance }\end{array}$ & 89.31 & 8.14 & 1.84 & \multicolumn{2}{|c|}{0.71} \\
\hline Cumulative & 89.31 & 97.45 & 99.29 & \multicolumn{2}{|c|}{100} \\
\hline \multicolumn{6}{|c|}{ Output (b) } \\
\hline Output variable & PC1 & PC2 & PC3 & PC4 & PC5 \\
\hline No. of admissions & -0.463 & 0.464 & -0.138 & 0.396 & -0.628 \\
\hline No. of in-patient & -0.463 & -0.219 & -0.287 & -0.771 & -0.245 \\
\hline Total Caesarian & -0.452 & -0.324 & -0.542 & 0.415 & 0.474 \\
\hline Total cardiovascular & -0.442 & 0.582 & 0.347 & -0.204 & 0.551 \\
\hline Total beneficiary DCC & -0.414 & -0.541 & 0.696 & 0.185 & -0.131 \\
\hline Proportion of variance & 79.48 & 9.68 & 7.03 & 3.16 & 0.66 \\
\hline Cumulative & 79.48 & 89.16 & 96.19 & 99.34 & 100 \\
\hline
\end{tabular}

Source: R programming.

Table 3 presents the efficiency scores calculated using BCC-Input model. In the first model efficiency scores are calculated using the original data, this model gives 17 efficient DMUs and 7 inefficient DMUs. The second model which represents $90 \%$ of information from the first PC for input and $80 \%$ of information for the first PC for output provides 3 DMUs as efficient and 21 as inefficient. Model 3 where $90 \%$ of information holds for input and outputs provides 9 DMUs as efficient and 15 DMUs as inefficient. The next two models which respectively includes 2 and 3 PCs related to input and output which explains most of the variance reveals 10 and 15 DMUs as efficient. It is observed that the results vary very much when complete information was not utilized. Specifically, the number of efficient units varies very much (model 2) when one PC is used. So use of PCA in DEA helps us to differentiate between efficient and inefficient DMUs and strengthens the discrimination power of DEA.

Table 3. Efficiency scores and rank of PCA-DEA with BCC-I model

\begin{tabular}{|c|c|c|c|c|c|c|c|c|c|c|c|}
\hline \multirow[t]{2}{*}{$\begin{array}{l}\text { No } \\
\text {. }\end{array}$} & \multirow[t]{2}{*}{ DMU } & \multicolumn{2}{|c|}{$\begin{array}{l}\text { model 1: } \\
\text { original data }\end{array}$} & \multicolumn{2}{|c|}{$\begin{array}{l}\text { model 2: } 1 \text { PC } \\
\text { input m } 1 \text { PC } \\
\text { output }\end{array}$} & \multicolumn{2}{|c|}{$\begin{array}{l}\text { model 3: } 1 \text { PC } \\
\text { input m } 2 \text { PCs } \\
\text { output }\end{array}$} & \multicolumn{2}{|c|}{$\begin{array}{l}\text { model 4: } 2 \\
\text { PCs input m } 2 \\
\text { PCs output }\end{array}$} & \multirow{2}{*}{$\begin{array}{l}\text { model 5: } \\
\text { input m } \\
\text { output }\end{array}$} & \multirow{2}{*}{$\begin{array}{ll}3 & \text { PCs } \\
3 & \text { PCs } \\
& \\
\text { Rank }\end{array}$} \\
\hline & & Score & Rank & Score & Rank & Score & $\begin{array}{l}\text { Ran } \\
\mathbf{k}\end{array}$ & Score & $\begin{array}{l}\text { Ran } \\
\mathbf{k}\end{array}$ & & \\
\hline 1 & Aaley & $\begin{array}{l}0.606 \\
5\end{array}$ & 22 & 0.8593 & 11 & 1 & 1 & 1 & 1 & 1 & 1 \\
\hline 2 & Akkar & 1 & 1 & 0.4986 & 19 & 0.9587 & 15 & 0.9587 & 17 & 0.9587 & 20 \\
\hline
\end{tabular}




\begin{tabular}{|c|c|c|c|c|c|c|c|c|c|c|c|}
\hline 3 & Baabda & 1 & 1 & 0.5428 & 18 & 0.8842 & 21 & 0.8842 & 21 & 0.8987 & 21 \\
\hline 4 & Baalbek & 1 & 1 & 0.2095 & 23 & 1 & 1 & 1 & 1 & 1 & 1 \\
\hline \multirow[t]{2}{*}{5} & Batroun & 0.898 & 19 & & & & & & & & \\
\hline & & 8 & & 0.9356 & 8 & 0.9677 & 13 & 0.9766 & 13 & 0.9848 & 17 \\
\hline 6 & Bcharreh & 1 & 1 & 0.9936 & 5 & 1 & 1 & 1 & 1 & 1 & 1 \\
\hline 7 & Beirut & 1 & 1 & 1 & 1 & 1 & 1 & 1 & 1 & 1 & 1 \\
\hline 8 & Bent Jbayl & 1 & 1 & 0.6599 & 16 & 1 & 1 & 1 & 1 & 1 & 1 \\
\hline \multirow[t]{2}{*}{9} & Chouf & 0.834 & 20 & & & & & & & & \\
\hline & & 8 & & 0.5867 & 17 & 1 & 1 & 1 & 1 & 1 & 1 \\
\hline 10 & Hasbaiya & 1 & 1 & 0.9588 & 7 & 0.9838 & 11 & 0.9838 & 11 & 1 & 1 \\
\hline 11 & Hermel & 1 & 1 & 0.7582 & 14 & 0.8995 & 18 & 0.9549 & 18 & 1 & 1 \\
\hline \multirow[t]{2}{*}{12} & Jbayl & 0.672 & 21 & & & & & & & & \\
\hline & & 6 & & 0.9703 & 6 & 0.9806 & 12 & 0.9836 & 12 & 0.9842 & 18 \\
\hline 13 & Jezzine & 1 & 1 & 1 & 1 & 1 & 1 & 1 & 1 & 1 & 1 \\
\hline 14 & Keserwan & 0.464 & 24 & 0.9985 & 4 & 0.9993 & 10 & 1 & 1 & 1 & 1 \\
\hline 15 & Koura & 1 & 1 & 0.875 & 10 & 0.9182 & 17 & 0.9766 & 13 & 1 & 1 \\
\hline 16 & Marjaayou & 1 & 1 & & & & & & & & \\
\hline \multirow{2}{*}{17} & & & 23 & 0.7751 & 13 & 0.9633 & 14 & 0.9633 & 16 & 0.9999 & 16 \\
\hline & & $\begin{array}{l}0.481 \\
2\end{array}$ & & 1 & 1 & 1 & 1 & 1 & 1 & 1 & 1 \\
\hline 18 & Nabatiyeh & 1 & 1 & 0.4329 & 21 & 0.6271 & 24 & 0.6395 & 24 & 0.7713 & 24 \\
\hline 19 & Rachaiya & 1 & 1 & 0.9136 & 9 & 0.9522 & 16 & 0.9713 & 15 & 1 & 1 \\
\hline 20 & Saida & 1 & 1 & 0.2611 & 22 & 0.7763 & 23 & 0.7769 & 23 & 1 & 1 \\
\hline 21 & Sour & 1 & 1 & 0.4494 & 20 & 0.886 & 20 & 0.886 & 20 & 0.886 & 22 \\
\hline 22 & Tripoli & 1 & 1 & 0.1787 & 24 & 1 & 1 & 1 & 1 & 1 & 1 \\
\hline 23 & West Beqaa & 1 & 1 & 0.739 & 15 & 0.8172 & 22 & 0.8389 & 22 & 0.8555 & 23 \\
\hline \multirow[t]{2}{*}{24} & Zgharta & 0.963 & 18 & & & & & & & & \\
\hline & & 3 & & 0.8256 & 12 & 0.8976 & 19 & 0.9504 & 19 & 0.9685 & 19 \\
\hline \multicolumn{2}{|c|}{$\begin{array}{l}\text { Nb. of efficient } \\
\text { DMUs }\end{array}$} & \multicolumn{2}{|c|}{17} & \multicolumn{2}{|c|}{3} & \multicolumn{2}{|c|}{9} & \multicolumn{2}{|c|}{10} & \multicolumn{2}{|c|}{15} \\
\hline \multicolumn{2}{|c|}{$\begin{array}{c}\text { Nb. of inefficient } \\
\text { DMUs }\end{array}$} & \multicolumn{2}{|c|}{7} & \multicolumn{2}{|c|}{21} & \multicolumn{2}{|c|}{15} & \multicolumn{2}{|c|}{14} & \multicolumn{2}{|c|}{9} \\
\hline
\end{tabular}

Source: DEA solver.

\section{3 results of different models $P C A-D E A$}

In this part of the paper we show the list of efficient DMUs and that of inefficient DMU for each model (Table 4). The results show that Beirut, Matn and Jezzine are the efficient DMU in model 2 and the other PCA-DEA model. Whereas Matn is not an efficient DMU in model 1 using original data.

Table 4. Results of different models

\begin{tabular}{|c|c|c|c|}
\hline Model no. & $\begin{array}{l}\text { Nb. of } \\
\text { efficient } \\
\text { DMUs }\end{array}$ & $\begin{array}{l}\text { Nb. of } \\
\text { inefficient } \\
\text { DMUs }\end{array}$ & Efficient qada \\
\hline 1: original data & 17 & 7 & $\begin{array}{l}\text { Beirut, Baabda, Akkar, Bcharreh, Koura, Tripoli, } \\
\text { Baalbek, Hermel, Rachaiya, West Beqaa, } \\
\text { Hasbaiya, Jezzine, Saida, Sour, Bent Jbay, } \\
\text { Marjaayoun, Nabatiyeh. }\end{array}$ \\
\hline $\begin{array}{l}\text { 2: } 1 \text { PC input m } 1 \\
\text { pc output }\end{array}$ & 3 & 21 & Beirut, Matn, Jezzine \\
\hline
\end{tabular}




$\begin{array}{llll}\begin{array}{l}\text { 3: } \mathbf{1} \text { PC input m } 2 \\ \text { pc output }\end{array} & 9 & 15 & \begin{array}{l}\text { Beirut, Aaley, Babda, Chouf, Keserwan, Matn, } \\ \text { Tripoli, Baalbek, Jezzine, Saida. }\end{array}\end{array}$

4: 2 PC input $\mathrm{m} 2$ pe output

10

14

Beirut, Aaley, Chouf, Keserwan, Matn, Bcharreh, Tripoli, Baalbek, Jezzine, Bent Jbayl

\section{5: 3 PC input $\mathrm{m} 3$ pe output}

15
9
Beirut, Aaley, Chouf, Keserwan, Matn, Bcharreh, Koura, Tripoli, Baalbek, Hermel, Rachaiya, Hasbaiya, Jezzine, Saida Bent Jbayl

Source: results of DEA solver.

\subsection{Benchmarking and Ranking of Qada's Hospitals Based on Model-2}

For the purpose of benchmarking we used model-2 where one PC input and one PC output are using. Table 5 shows the reference set and corresponding weights of the inefficient Hospitals. For improvement, the inefficient DMUs can follow their reference set. Based on model-2 DMUs (Beirut, Matn and Jezzine) are efficient and these DMUs act as a peer for remaining 21 inefficient DMUs.

For example, qada number 2 is an inefficient and it has two reference hospitals 7 and 19 with weights 0.569 and 0.431 respectively. qada number 2 can follow any of these two qadas for improving. Similarly, other inefficient hospitals have their reference set.

Ranking the qadas based on efficiency scores and peer counts to inefficient and efficient hospitals respectively. Therefore, first rank is given for efficient qada which acts as a peer for maximum number of inefficient qadas. qada 7 is peer for 21 inefficient hospitals, receives first rank and qada number 19 is peer for 15 inefficient hospitals receives the second two and qada number 1 is peer for 8 qadas receives rank 3 .

Table 5. Benchmarking and ranking of hospitals

\begin{tabular}{llllllll}
\hline No. & DMU & Score & Rank & & Reference(peer weights) & \\
\hline $\mathbf{1}$ & Beirut & $\mathbf{1}$ & $\mathbf{3}$ & Beirut & 1 & & \\
2 & Aaley & 0.8593 & 11 & Matn & 0.569 & Jezzine & 0.431 \\
3 & Baabda & 0.5428 & 18 & Beirut & 0.569 & Matn & 0.431 \\
4 & Chouf & 0.5867 & 17 & Matn & 0.934 & Jezzine & 0.066 \\
5 & Jbayl & 0.9703 & 6 & Matn & 0.191 & Jezzine & 0.809 \\
6 & Keserwan & 0.9985 & 4 & Matn & 0.345 & Jezzine & 0.655 \\
$\mathbf{7}$ & Matn & $\mathbf{1}$ & $\mathbf{1}$ & Matn & 1 & & \\
8 & Akkar & 0.4986 & 19 & Beirut & 0.091 & Matn & 0.909 \\
9 & Batroun & 0.9356 & 8 & Matn & 0.172 & Jezzine & 0.828 \\
10 & Bcharreh & 0.9936 & 5 & Matn & 0.011 & Jezzine & 0.989 \\
11 & Koura & 0.875 & 10 & Matn & 0.413 & Jezzine & 0.587 \\
12 & Tripoli & 0.1787 & 24 & Beirut & 1 & & \\
13 & Zgharta & 0.8256 & 12 & Matn & 0.452 & Jezzine & 0.548 \\
14 & Baalbek & 0.2095 & 23 & Beirut & 0.844 & Matn & 0.156 \\
15 & Hermel & 0.7582 & 14 & Matn & 0.506 & Jezzine & 0.494 \\
16 & Rachaiya & 0.9136 & 9 & Matn & 0.194 & Jezzine & 0.806 \\
17 & West Beqaa & 0.739 & 15 & Matn & 0.55 & Jezzine & 0.45 \\
18 & Hasbaiya & 0.9588 & 7 & Matn & 0.075 & Jezzine & 0.925 \\
\hline
\end{tabular}




\begin{tabular}{llllllll}
\hline $\mathbf{1 9}$ & Jezzine & $\mathbf{1}$ & $\mathbf{2}$ & Jezzine & 1 & & \\
20 & Saida & 0.2611 & 22 & Beirut & 0.84 & Matn & 0.16 \\
21 & Sour & 0.4494 & 20 & Beirut & 0.174 & Matn & 0.826 \\
22 & Bent Jbayl & 0.6599 & 16 & Matn & 0.679 & Jezzine & 0.321 \\
23 & Marjaayoun & 0.7751 & 13 & Matn & 0.448 & Jezzine & 0.552 \\
24 & Nabatiyeh & 0.4329 & 21 & Beirut & 0.235 & Matn & 0.765 \\
\hline
\end{tabular}

Source: $\overline{\mathrm{DEA} \text { solver }}$

Table 6 shows the Return to Scale characteristics for each DMU. DMUnumber 1 and 12 show constant return to scale, whereas all the other DMUs show decreasing Return to scale.

Table 6. Return to scale of DMUs

\begin{tabular}{llll}
\hline No. & DMU & Score & RTS of Projected DMU \\
\hline 1 & Beirut & 1 & Constant \\
2 & Aaley & 0.8593 & Decreasing \\
3 & Baabda & 0.5428 & Decreasing \\
4 & Chouf & 0.5867 & Decreasing \\
5 & Jbayl & 0.9703 & Decreasing \\
6 & Keserwan & 0.9985 & Decreasing \\
7 & Matn & 1 & Decreasing \\
8 & Akkar & 0.4986 & Decreasing \\
9 & Batroun & 0.9356 & Decreasing \\
10 & Bcharreh & 0.9936 & Decreasing \\
11 & Koura & 0.875 & Decreasing \\
12 & Tripoli & 0.1787 & Constant \\
13 & Zgharta & 0.8256 & Decreasing \\
14 & Baalbek & 0.2095 & Decreasing \\
15 & Hermel & 0.7582 & Decreasing \\
16 & Rachaiya & 0.9136 & Decreasing \\
17 & West Beqaa & 0.739 & Decreasing \\
18 & Hasbaiya & 0.9588 & Decreasing \\
19 & Jezzine & 1 & Decreasing \\
20 & Saida & 0.2611 & Decreasing \\
21 & Sour & 0.4494 & Decreasing \\
22 & Bent Jbayl & 0.6599 & Decreasing \\
23 & Marjaayoun & 0.7751 & Decreasing \\
24 & Nabatiyeh & 0.4329 & Decreasing \\
\hline & & & \\
\hline
\end{tabular}

Source: DEA solver.

\section{Conclusion}

The present paper aimed at analyzing the efficiency of Hospitals in Lebanon for the year 2016. For this purpose, a non-parametric technique DEA is used. In DEA, the number of efficient decision making units increases when there are more number of inputs and outputs in respect of the number of DMUs. To overcome this problem, an integrated PCA with DEA is used in this study. PCA is applied to all inputs and separately to all outputs. Efficiency of the hospital is found using variable return to scale input orientation by both traditional DEA and PCA-DEA.

As result of this study, we found that out of 24 Hospital's qada 17 are efficient in traditional DEA model, whereas only 3 hospitals are efficient using PCA-DEA model with 1 PC on input and output case. We compare also different 
models using more number of PCs for input and output. It is clear that when the number of PCs increases, the results are more similar to using original data without data reduction. This indicates when we have large number of variables PCA-DEA is preferable to discriminate between efficient and inefficient than traditional DEA. It may be concluded that the use of principal components can considerably improve the strength of DEA models.

\section{Acknowledgments}

This research was funded by the Lebanese University.

\section{References}

Adler, N., \& Golany, B. (2002). Including principal component weights to improve discrimination in data envelopment analysis. Journal of Operational Research Society, 53, 985-91. https://doi.org/10.1057/palgrave.jors.2601400

Afonso, \& Aubyn, M. St. (2005). Non-parametric approaches to education and health efficiency in OECD countries. Journal of Applied Economics, 8(2), 227.

Ali AI, \& Seiford, L. M. (1990). Translation invariance in data envelopment analysis. Operations Research Letters, 9, 403-405. https://doi.org/10.1016/0167-6377(90)90061-9

Ammar, W. (2009). Health Reform in Lebanon Key Achievements at a Glance, Ministry of Public Health, Mueang Nonthaburi, Thailand.

Annapoorni, D., \& Prakash, V. (2016, December). Measuring the Performance Efficiency of Hospitals: PCA DEA Combined Model Approach. Indian Journal of Science and Technology, 9(S1). https://doi.org/10.17485/ijst/2016/v9iS1/93159

Antonios, D., \& Mikhael, M. (2018, April 20). The Lebanese Healthcare Sector: In Urgent Need of Reforms, blominvest bank.

Asandului, L., Roman, M., \& Fatulescu, P. (2014). The efficiency of healthcare systems in Europe: a data envelopment analysis approach. Procedia Economics and Finance, 10, 261-268. https://doi.org/10.1016/S2212-5671(14)00301-3

Banker, R. D., \& Charnes, A., \& Cooper, W. W. (1984). Models for Estimation of Technical and Scale Inefficiencies in Data Envelopment Analysis. Management Science, 30(1984), 1078-1092. https://doi.org/10.1287/mnsc.30.9.1078

Central administration of Statistics CAS (2009). Household Survey. www.cas.gov.lb.

Jill, Johnes. (2006). Data envelopment analysis and its application to the measurement of efficiency in higher $\begin{array}{llll}\text { education. } & \text { Economics } & \text { 273-288. }\end{array}$ https://doi.org/10.1016/j.econedurev.2005.02.005

Jolliffe I. T. (1986). Principal Component Analysis and Factor Analysis. In: Principal Component Analysis, Springer Series in Statistics. Springer, New York, NY. https://doi.org/10.1007/978-1-4757-1904-8_7

Kordrostami, S. (2011). Evaluating the Efficiency of DMUs with PCA and an Application in Real Data Set of Iranian Banks. Int. J. Industrial Mathematics, 3(4), 251-258.

Morrisette, S., Oberman, W. D., Watts, A. D., \& Beck, J. B. (2015). Health care: a brave new world. Health Care Analysis, 23(1), 88-105. https://doi.org/10.1007/s10728-013-0244-5.

Mustapha, D. I., \& Sahand, D. (2018). Efficiency Analysis of Healthcare System in Lebanon Using Modified Data Envelopment Analysis. Journal of Healthcare Engineering, 6. https://doi.org/10.1155/2018/2060138. https://doi.org/10.1155/2018/2060138

Pourreza, V., Alipour, J., Arabloo, M. Bayati, \& Ahadinezhad, B. (2017). Health production and determinants of health systems performance in WHO Eastern Mediterranean Region. Eastern Mediterranean Health Journal, 23(5), 368-374. https://doi.org/10.26719/2017.23.5.368

Reindel, S., \& Zucco, M. (2010). Healthcare in Lebanon: healthcare in Lebanon guiding principle. http://lexarabiae.meyer-reumann.com/blog/2010-2/healthcare-in-lebanon.

Salti, N., Chaaban, J., \& Raad, F. (2010). Health equity in Lebanon: a microeconomic analysis. International Journal for Equity in Health, 9(1), 11. https://doi.org/10.1186/1475-9276-9-11

Sen, K., \& Mehio-Sibai, A. (2004). Transnational capital and confessional politics: the paradox of the health care system in Lebanon. International Journal of Health Services, 34(3), 527-551. https://doi.org/10.2190/6X2V- 


\section{GE4T-9BQF-WYXB}

UNHCR (December 2017). Syria Regional Refugee. http://data.unhcr.org/syrianrefugees/ regional.php.

Zhu, J. (1998). Data Envelopment Analysis Vs Principal Component Analysis: An Illustrative Study of Economic Performance of Chinese Cities. European Journal of Operational Research, 111, 50-61. https://doi.org/10.1016/S0377-2217(97)00321-4

Zijiang, Y. (2009). Bank Branch Operating Efficiency: A DEA Approach, Proceedings of the International MultiConference of Engineers and Computer Scientists 2009 Vol II IMECS 2009, March 18 - 20, 2009, Hong Kong.

\section{Copyrights}

Copyright for this article is retained by the author(s), with first publication rights granted to the journal.

This is an open-access article distributed under the terms and conditions of the Creative Commons Attribution license (http://creativecommons.org/licenses/by/4.0/). 